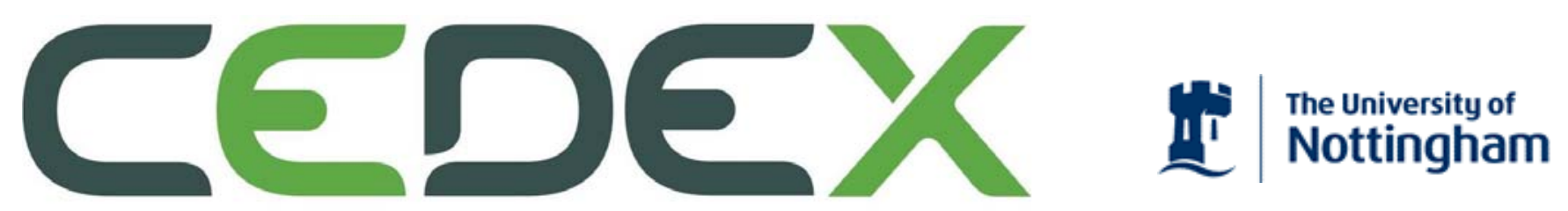

CENTRE FOR DECISION RESEARCH \& EXPERIMENTAL ECONOMICS

Discussion Paper No. 2009-21

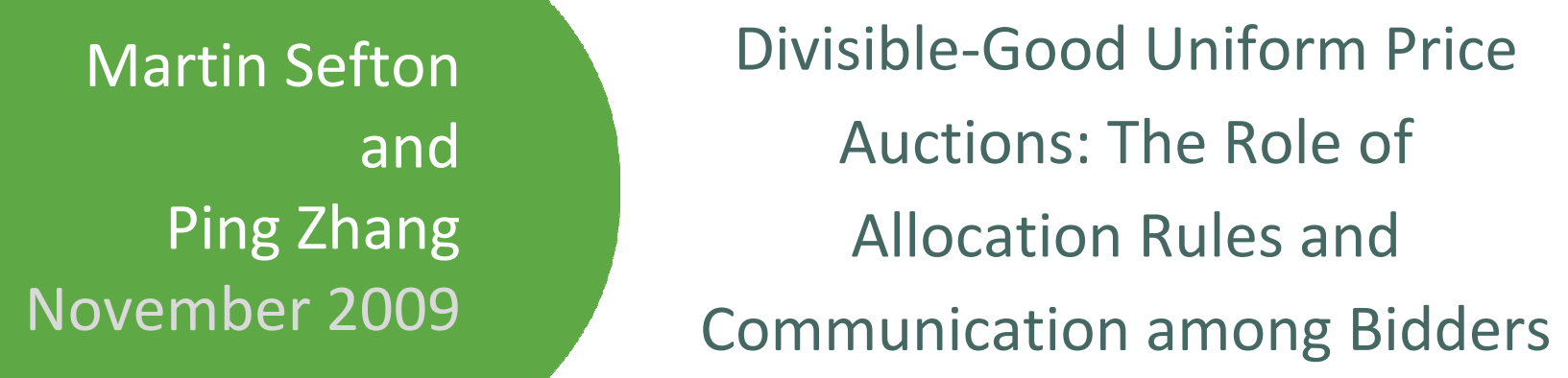

CeDEx Discussion Paper Series 

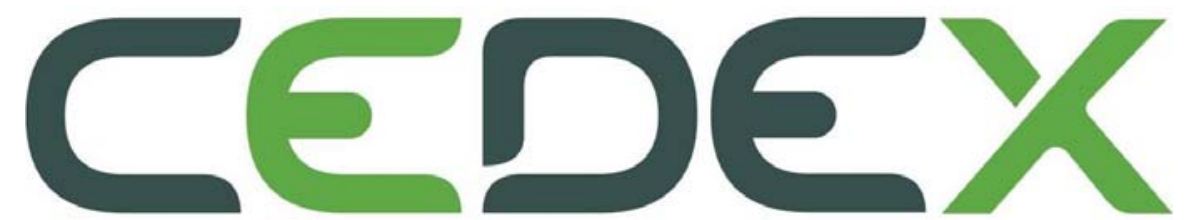

CENTRE FOR DECISION RESEARCH \& EXPERIMENTAL ECONOMICS

The Centre for Decision Research and Experimental Economics was founded in 2000, and is based in the School of Economics at the University of Nottingham.

The focus for the Centre is research into individual and strategic decision-making using a combination of theoretical and experimental methods. On the theory side, members of the Centre investigate individual choice under uncertainty, cooperative and non-cooperative game theory, as well as theories of psychology, bounded rationality and evolutionary game theory. Members of the Centre have applied experimental methods in the fields of public economics, individual choice under risk and uncertainty, strategic interaction, and the performance of auctions, markets and other economic institutions. Much of the Centre's research involves collaborative projects with researchers from other departments in the UK and overseas.

Please visit http://www.nottingham.ac.uk/economics/cedex/ for more information about the Centre or contact

Karina Terry

Centre for Decision Research and Experimental Economics

School of Economics

University of Nottingham

University Park

Nottingham

NG7 2RD

Tel: +44 (0) 1159515620

Fax: +44 (0) 1159514159

karina.terry@nottingham.ac.uk

The full list of CeDEx Discussion Papers is available at http://www.nottingham.ac.uk/economics/cedex/papers/index.html 


\title{
Divisible-good uniform price auctions: the role of allocation rules and communication among bidders
}

\author{
Martin Sefton*, Ping Zhang*
}

\begin{abstract}
We use laboratory experiments to compare allocation rules in uniform price divisible good auctions. "Standard" and "uniform" allocation rules admit different types of low-price equilibria, which are eliminated by a "hybrid" rule. We observe little evidence of revenue differences among the allocation rules. Under all three allocation rules, prices are competitive when bidders cannot explicitly communicate, and collusive when bidders can explicitly communicate. With explicit communication we find that collusive agreements are more fragile when the gain from a unilateral deviation is larger. We also find that the standard allocation rule is particularly vulnerable to collusive equilibria.
\end{abstract}

Keywords: experiment, uniform price auction, multi-unit auction, divisible-good auction, allocation rule, communication

JEL Classifications: D44( Auctions), C72(Noncooperative Games), C92 (Laboratory, Group Behavior)

Acknowledgement: We thank participants at the 2009 Economic Science Association International Meeting in Washington D.C., the 2009 International Conference on Game Theory in New York for helpful comments. Support from the ESRC under grant PTA-026-27-1408 is gratefully acknowledged.

*School of Economics, University of Nottingham, University Park, Nottingham NG7 2RD, UK 


\section{INTRODUCTION}

Uniform Price Auctions are widely used for selling a variety of assets, such as Treasury bills, spectrum, initial public offerings and pollution permits. A potential drawback of this auction format is the existence of low-price equilibria which can result in large underpricing and severely reduce seller revenue (Wilson, 1979). Recently, Kremer and Nyborg (2004a, 2004b) point out that the extent of equilibrium underpricing is sensitive to the allocation rule, and in particular how excess demand is rationed. In Kremer and Nyborg (2004a) they show that the standard allocation rule, whereby bids placed above the market price are fully fulfilled and the rest of units are rationed among bids placed at the market price, may inhibit competition. In contrast, they show that a simple uniform allocation rule, where rationing applies to all winning bids (bids placed either above or at the market price), encourages a Bertrand-like competition among bidders and thus eliminates the low-price equilibria. However, when bidders are capacity constrained the uniform allocation rule admits another set of low-price equilibria in which all bidders bid for their capacity at a low price. In this case Kremer and Nyborg (2004b) suggest that a hybrid allocation rule, a weighted average of the uniform and standard allocation rules, fosters price competition and eliminates underpricing. In this paper we compare these alternative allocation rules in laboratory experiments.

In our first set of experiments we compare the three allocation rules in a three-bidder setting with limited communication among bidders. We find little difference in prices across allocation rules. For all three rules we observe aggressive bidding which results in high prices. There is little evidence of low-price equilibria or, more generally, of low price outcomes being attained.

In our second set of experiments we studied a setting that may be more conducive to coordination on low-price equilibria, namely one in which we introduced richer possibilities for communication by allowing bidders to send messages through a chat box before submitting bids. In this set of experiments coordinated strategies predominate and the market price drops dramatically under all three allocation rules. Analysis of individual behavior shows that this is not necessarily due to the play of low-price equilibrium strategies, but rather we see that bidders are often able to coordinate on non-equilibrium agreements that are apparently difficult to achieve and maintain without chat opportunities. These non-equilibrium agreements typically involve bidders submitting flat demand curves. We also see that some agreements are broken, and agreements are more fragile the larger the potential gain from a unilateral deviation. 
However, a structural feature of uniform price auctions is that low-price outcomes may be maintained even if some bidders renege on an agreement. In fact we observe collusive prices even in groups where collusive agreements were broken.

In our third set of experiments we retained chat opportunities but increased the number of bidders from three to six. We find that bidders are less cooperative than in the three-bidder case, in the sense that non-equilibrium agreements are honored less frequently. While many subjects keep to a non-equilibrium agreement to bid low, some 'cheat' and raise their bids, although this has only a weak effect on price. We do however see some differences in behavior between small and large groups. In larger groups bidders no longer rely on flat demand curves, but instead coordinate on steep demand curves that are less vulnerable to deviation. In particular under the standard allocation rule, low-price equilibria involving steep demand curves are observed even with six bidders.

The experimental literature on multi-unit uniform price auctions goes back to Smith (1967). Much of this literature compares the standard uniform price auction with discriminatory auctions and focuses on private value settings. Goswami, Noe, and Rebello (1996) study the effect of nonbinding pre-play communication in a common value setting similar to ours, and our results add to their evidence on how communication affects auction performance in this important setting. As far as we are aware ours is the first experimental study of uniform or hybrid allocation rules.

The remainder of the paper is organized as follows. In the next Section we briefly review the theoretical background on which our experiment is based. In Section 3 we describe our experimental design and procedures. In Section 4 we report the results, and in Section 5 we conclude.

\section{THEORETICAL BACKGROUND}

\subsection{Equilibrium Underpricing and Auction Rules}

Low-price equilibria in uniform price auctions were identified by Wilson (1979) in the context of share auctions. The basic idea is simple. In standard uniform price auctions bidders submit demand functions, and the market price is determined as the highest price such that aggregate demand is at least equal to supply. Demand for units at prices above the market price is fully fulfilled, and demand at the market price is rationed pro rata among marginal bids. By submitting inelastic demand functions that just clear the market, any attempt by a bidder to increase her allocation will cause a large increase in price. When the aggregate demand function is steep 
enough any deviation is not profitable and a low price can be sustained in equilibrium. Further theoretical work has demonstrated the generality of Wilson's results by showing the existence of a continuum of low-price equilibria under different information structures, risk attitudes, supply uncertainty, and continuous/discrete demand functions (see Klemperer and Meyer (1989), Back and Zender (1993), Wang and Zender (2002), Ausubel and Cramton (2004)).

Kremer and Nyborg (2004a) show that low-price equilibria can be eliminated by using a uniform allocation rule so that demand at and above the market price is rationed pro rata. By bidding for the same amount at a slightly higher price than the market price, a bidder can increase her allocation at the cost of a small increase in price. Thus this rule induces price competition at the margin and eliminates low-price equilibria.

A potential problem with the uniform allocation rule arises if bidders are capacity constrained. In this case there is another set of equilibria that result in a low price. These are 'single-bid equilibria' where bidders bid for their capacity at a common price. If a bidder's capacity is less than the total number of units for sale she cannot increase either the market price or her allocation by increasing her bid. Thus there is no incentive to deviate and the common price is an equilibrium price. Kremer and Nyborg (2004b) suggest that a rule that incorporates properties of both allocation rules, for example, a weighted average of the two rules, encourages competition both above and at the margin and thus eliminates both types of low-price equilibria.

The example below illustrates all of this. The example closely follows Kremer and Nyborg's (2004b), which in turn is consistent with the basic share auction model of Wilson (1979) and Back and Zender (1993) where a perfectly divisible good with a common value is sold to a group of symmetric buyers. Kremer and Nyborg adapted the model to a discrete structure in both quantity and price dimensions and, for simplicity, considered the case where all bidders are risk neutral and completely informed of the common value before submitting bids.

\subsection{An Example}

There are 25 units for sale. There are three bidders and each bidder can bid for up to 24 units. Units have a common value of $\$ 10$ per unit. Bidders can place a bid at any integer price between 0 and 10 for any integer quantity between 0 and 24. Each bidder can submit multiple bids, as long as the total number of units bid for does not exceed 24 . The market price is the highest price where aggregate demand is greater than or equal to 25 . If the aggregate demand at a price of zero is less than 25 units the market price is zero and each bidder obtains the number of units she bids 
for. Otherwise the allocation may differ under different allocation rules.

\subsubsection{Standard Allocation Rule}

Under the standard allocation rule (STANDARD), when demand exceeds supply, bids placed above the market price are fully fulfilled. Then the remaining units are allocated proportionately among the bid(s) placed at the market price. Suppose all three bidders bid for 8 units at a price of $\$ 10$ and 16 units at a price of $\$ 0$. Then the market price is zero. (At prices exceeding zero aggregate demand is 24 and supply is 25.) Each bidder bids for 8 units at prices above the market price, and so immediately receives 8 units. One unit is left to be allocated proportionately, so each bidder also receives a further $1 / 3$ unit.

In fact, these bids constitute an equilibrium. Each bidder earns $\$ 83.33$. The most profitable unilateral deviation would be for a bidder to bid for 8 units at a price of $\$ 10$ and 16 units at a price of $\$ 1$. Then the market price would be $\$ 1$ and this bidder would be allocated 9 units. Her earnings would be $\$ 81$, and so this deviation is not profitable. We refer to this type of equilibrium as a "Tacit Collusion Equilibrium" (TCE); similar strategies can support TCE prices at any price below $\$ 10 .^{1}$

Notice that all bidders bidding for 24 units at $\$ 10$ is also an equilibrium, and in this each bidder obtains one third of the units for sale at a price of $\$ 10$. Submitting flat demand functions at any other price cannot support an equilibrium, as bidders would have an incentive to submit a flat demand function at a higher price.

\subsubsection{Uniform Allocation Rule}

Under the uniform allocation rule (UNIFORM), the units for sale are allocated proportionately among all winning bids, i.e. bids placed either above or at the market price. Suppose, as before, all three bidders bid for 8 units at a price of $\$ 10$ and 16 units at a price of $\$ 0$. Then the market price is zero, and the aggregate demand is 72 units at this price. Thus each bidder is awarded 25 $\times 24 / 72$ units, or 8.33 units. Each bidder earns $\$ 83.33$.

This is not a Nash equilibrium under UNIFORM. By bidding for 8 units at $\$ 10$ and 16 units at $\$ 1$ a bidder could raise her allocation from $25 \times 24 / 72$ units to $25 \times 24 / 40$ units while

\footnotetext{
1 Any strategies supporting an equilibrium price below 10 under this allocation rule are termed TCE strategies. These strategies use high inframarginal bids to support a market price below 10. For example to sustain an equilibrium price of 9, each bidder might demand 8 units at a price of 10 and 16 at a price of 9. In general a TCE requires that the total number of units requested at prices exceeding the market price is 24 (otherwise a bidder could increase her allocation without raising the market price), and moreover these inframarginal bids must be placed at sufficiently high prices.
} 
increasing the price from $\$ 0$ to $\$ 1$ : this would increase her earnings to $\$ 135$. Similarly other strategies that form a TCE under the standard allocation rule are not equilibria under UNIFORM. Although some TCE strategies remain equilibria under UNIFORM, the lowest price that can be supported by such strategies is $\$ 8$. $^{2}$

However, because bidders are capacity constrained, there exists another type of equilibrium. Suppose that every bidder bids for 24 at price 0 . Each bidder receives 8.33 units at a price of $\$ 0$. It is easy to see that no bidder could raise the market price by deviating since the maximum quantity she can bid for is 24 and there are 25 units for sale. Whatever she bids, aggregate demand at prices above zero would still be less than 25 . Also, since bids placed above and at the market price are treated equally, as long as the bidder bids for 24 units she would still obtain the same allocation. Similarly, if all bidders bid for 24 units at a common price, this constitutes a Nash equilibrium, and so any market price can be sustained as a Nash equilibrium. We refer to this type of equilibrium as a "Single Bid Equilibrium" (SBE).

\subsubsection{Hybrid Allocation Rule}

Kremer and Nyborg (2004b) further suggest a hybrid allocation rule (HYBRID), which is a weighted average of the STANDARD and UNIFORM. In our experiment we use the simple average of the other two allocation rules.

This allocation rule incorporates advantages of both the other two allocation rules and as a result, it reduces the scope for both types of low-price equilibria. Like STANDARD, the HYBRID rule discriminates in favor of inframarginal demand, and this eliminates single-bid underpricing equilibria, while as in UNIFORM a bidder can significantly increase her allocation with a negligible increase in price, and this reduces the scope for TCE. As Kremer and Nyborg (2004b) note, the HYBRID rule "creates incentives for bidders to be aggressive above as well as on the margin" (p.865). For the example, bidding for 24 units at a price of $\$ 10$ is an equilibrium strategy, but there are no other SBE, and the lowest price that can be sustained by a TCE is $\$ 7$.

\subsection{Summary}

The example above is used in our experiment. In our experiment we also conduct auctions with six bidders. It is straightforward to obtain equilibria for different numbers of bidders. Table 1 gives the minimum equilibrium prices that can be sustained by TCE or SBE under each allocation rule. The maximum equilibrium price under all the three allocation rules is $\$ 10$. Any

\footnotetext{
${ }^{2}$ All TCE can be eliminated if the tick price is sufficiently small.
} 
price between the minimum and the maximum prices can be sustained in equilibrium.

Table 1. Minimum Equilibrium Prices Under Alternative Allocation Rules

\begin{tabular}{cccc|ccc}
\hline & \multicolumn{3}{c|}{3 bidders } & \multicolumn{3}{c}{6 bidders } \\
\cline { 2 - 7 } & Minimum & Minimum & Minimum & Minimum & Minimum & Minimum \\
TCE price & SBE price & $\begin{array}{c}\text { equilibrium } \\
\text { price }\end{array}$ & TCE price & SBE price & $\begin{array}{c}\text { equilibrium } \\
\text { price }\end{array}$ \\
\hline STANDARD & 0 & 10 & 0 & 4 & 10 & 4 \\
UNIFORM & 8 & 0 & 0 & 9 & 0 & 0 \\
HYBRID & 7 & 10 & 7 & 9 & 10 & 9 \\
\hline
\end{tabular}

The large set of equilibria makes the performance of uniform price auctions crucially depend on equilibrium selection. Although the theoretical literature has focused on collusive, or payoff dominant, equilibria, a large experimental literature has shown that subjects often fail to coordinate on payoff dominant equilibria (e.g. see Devetag and Ortmann (2007) for a review of coordination games.). There have been several private value auction experiments with two bidders and two units for sale where the market price is the highest losing price. The payoffdominant equilibrium requires subjects bid their private values for the first unit and zero for the second unit, but the common outcome of such experiments is that bidders bid at or above the value for the first unit, and bid lower than the value but higher than zero for the second unit (see Kagel and Levin (2001), Porter and Vragov (2006); Engelmann and Grimm (2009)). In general, collusive bidding is rarely observed in experimental uniform price sealed bid auctions. ${ }^{3}$ The evidence suggests collusion is only achievable if there are two bidders (Sherstyuk (2008); Kwasnica and Sherstyuk (2007)), subjects have a coordination device (Brown, Plott and Sullivan, 2009; Li and Plott, 2009), anonymity is abandoned (Füllbrunn and Neugebauer, 2007), auctions are open format (Goeree, Offerman and Sloof (2006), Burtraw et al. (forthcoming)), or bidders are allowed to communicate prior to bidding (Goswami, Noe and Rebello, 1996).

Pre-play communication has been shown to be an effective facilitating device in a wide range of settings. It increases coordination on payoff dominant equilibria in experimental coordination games (see Devetag and Ortmann, 2007) and sustains low prices in various experimental auctions (e.g. Isaac and Walker (1985), Kwasnica (2000), Burtraw et al. (forthcoming)). As we describe in the next section, we implement two types of pre-play communication in our experiment.

\footnotetext{
${ }^{3}$ For example see Zhang (2009), who finds no evidence that repeated play helps bidders coordinate on collusive strategies in a multi-unit uniform price auction with common values and four bidders.
} 


\section{EXPERIMENT}

\subsection{Experimental Design}

Our experiment is based on the example described in the previous section. In particular, as in Kremer and Nyborg, we focus on a one-shot game by having subjects bid in only one auction for which they are paid their earnings. Although the equilibrium analysis of the one-shot game is considerably less complex than the analysis of a repeated game, there remains a multiplicity of equilibria under all three allocation rules, and so it is unclear how subjects might coordinate on equilibrium. In order to provide better opportunity for equilibration, we preceded the auction by a series of 'practice' auctions, for which subjects were not paid.

We conducted three NC3 ('No Chat, 3 bidders') treatments, one for each allocation rule. In each NC3 treatment subjects were matched into groups of three and remained in this fixed group for 20 practice periods before a final 'real' period in which subjects were paid their earnings. As well as giving subjects experience with the experimental rules and environment, these practice periods allow subjects to communicate with other bidders via their decisions in previous periods. ${ }^{4}$ Note that in addition to providing limited communication opportunities, this design incorporates several other collusion facilitating factors: a small number of bidders, symmetry among bidders, complete information, and high expected gains from collusion (Sherstyuk, 1999). As we report later, despite these factors collusive behavior was rarely observed.

In our C3 ('Chat, 3 bidders') treatments we introduced more explicit communication possibilities by allowing subjects to send and receive messages through a chat box prior to bidding. Finally, in our C6 ('Chat, 6 bidders') treatments we examined the three allocation rules with groups of six bidders, using the same explicit communication possibilities as in the $\mathrm{C} 3$ treatments. Since collusion was rarely observed in our NC3 treatments we did not run further NC treatments with larger groups as there would be no reason to expect these to be less competitive than the NC3 groups. $^{5}$

\subsection{Procedures}

The experiment comprised 21 computerized sessions conducted at the University of Nottingham,

\footnotetext{
${ }^{4}$ Some previous experiments have found that subjects use such communication opportunities to attain more cooperative outcomes. For example, Burton and Sefton (2004) find that communication via decisions helps subjects coordinate on an efficient, but risky, equilibrium. In experimental multi-unit ascending auctions with private values Kwasnica and Sherstyuk (2007) find that repeated play allows subjects to signal and retaliate, fostering collusion.

${ }^{5}$ On the other hand, one might expect less collusion in C6 than C3. For example, Kwasnica and Sherstyuk (2007) found that the collusive behaviour observed in groups of two bidders failed in groups of five bidders.
} 
using a total of 342 subjects recruited from a university-wide pool of undergraduate students. ${ }^{6}$ Two sessions were conducted for each NC3 and C3 treatment and three sessions were conducted for each C6 treatment. This resulted in 10 groups of three bidders per treatment (NC3 and C3) and 9 groups of six bidders (C6) (see Table 2).

Table 2. Summary of Experimental Design

\begin{tabular}{|c|c|c|c|c|c|}
\hline NC3 Treatments: & $\begin{array}{c}\text { Practice } \\
\text { periods }\end{array}$ & $\begin{array}{c}\text { Chat } \\
\text { Allowed? }\end{array}$ & $\begin{array}{c}\text { Bidders } \\
\text { per group }\end{array}$ & $\begin{array}{c}\text { Number } \\
\text { of groups }\end{array}$ & $\begin{array}{c}\text { Number of } \\
\text { Subjects }\end{array}$ \\
STANDARD & 20 & No & 3 & 10 & 30 \\
UNIFORM & 20 & No & 3 & 10 & 30 \\
HYBRID & 20 & No & 3 & 10 & 30 \\
\hline C3 Treatments: & & & & & \\
STANDARD & 11 & Yes & 3 & 10 & 30 \\
UNIFORM & 11 & Yes & 3 & 10 & 30 \\
HYBRID & 11 & Yes & 3 & 10 & 30 \\
\hline C6 Treatments: & & & & & \\
STANDARD & 11 & Yes & 6 & 9 & 54 \\
UNIFORM & 11 & Yes & 6 & 9 & 54 \\
HYBRID & 11 & Yes & 6 & 9 & 54 \\
\hline Total & & & & & 342 \\
\hline
\end{tabular}

At the beginning of each session, subjects were given a written set of instructions that the experimenter read aloud. Subjects then were allowed to ask questions by raising their hands and speaking to the experimenter in private. At the beginning of the first period, subjects were assigned to groups of either three or six (depending on treatments) and stayed in these groups for the entire session. Subjects were not informed of the identities of the other group members in any period, and no information passed across groups.

In the treatments without chat subjects were not allowed to communicate with one another during the session, except via the decisions they entered on their terminals. The decision-making phase of the session consisted of twenty practice periods followed by one "real" period.

At the beginning of the treatments with chat, subjects were assigned a subject ID which identified messages in the chat stage. After four practice periods without explicit communication, bidders then played seven more practice periods which consisted of a four minute chat stage followed by the bidding stage. In each chat stage bidders could send and receive messages via a

\footnotetext{
${ }^{6}$ Subjects were recruited through the on-line recruiting system ORSEE(Greiner, 2004) and the experiment was programmed and conducted with the software z-Tree (Fischbacher, 2007). A copy of the experimental instructions and screenshots are provided in Appendix A.
} 
chat box. They were prohibited from revealing personal information or making threatening, insulting or offensive comments, but otherwise the chat was unrestricted. ${ }^{7}$ In these treatments there were eleven practice periods before the real period. ${ }^{8}$

For each group a period consisted of an auction with 25 units for sale, where the value of each unit to a bidder was 10 points. There was no time limit for submitting bids, and bidders could place bids at any integer price up to 10 points, for any integer number of units up to 24 units. Bidders could submit multiple bids as long as the total number of units bid for did not exceed 24. After all subjects had submitted their bids, the computer calculated the price and the allocation. Each subject was then informed of the bids submitted by her group, the market price, her allocation and her point earnings in the period. The period then ended and the next period began. Before the last period subjects were reminded that this was the last period and that their earnings would be based on points earned in this period.

Sessions lasted 90 minutes on average and each subject was paid a show up fee of $£ 5$ plus $£ 0.20$ per point for points earned in the last period. Thus, in the last period each group was bidding for 25 units worth $£ 2$ each. Subjects earned $£ 13.10$ on average, ranging from a minimum of $£ 5$ to a maximum of $£ 48.20$. ${ }^{9}$

\section{RESULTS}

\subsection{Prices and Allocations}

We begin by focusing on market prices in the payment period. ${ }^{10}$ Figure 1 presents histograms of prices by treatment. With the limited communication possibilities of our NC3 treatments, prices cluster at the high end of the price range and are not significantly different across allocation rules. ${ }^{11}$ When groups can chat prices are lower. In our C3 treatments the average price is 0.60 , and we find no significant differences across allocation rules $(\mathrm{p}=0.639)$; in our C6 treatments

\footnotetext{
${ }^{7}$ Subjects were told that they would forfeit their earnings if they violated these rules. An inspection of chat data reveals no instances where subjects violated these rules.

${ }^{8} \mathrm{We}$ did not provide the chat option from period one because we wanted to give subjects some experience with the experimental rules and environment before sending messages. Also, time constraints meant that we could not conduct as many practice periods as in our NC3 treatments.

${ }^{9}$ At the time of the experiment $£ 1 \approx \$ 1.45$.

${ }^{10} 99.3 \%$ of units auctioned were sold so there is a tight link between price, seller revenue, and average bidder profit. In all cases of treatment effects (or non-effects) concerning price, there are corresponding effects (or non-effects) in terms of seller revenue and average bidder profit. Raw data, including chat logs, are available at www.nottingham.ac.uk/economics/cedex/papers/supplement/szdata.html.

${ }^{11}$ A Kruskal-Wallis test yields a p-value of 0.647. Unless otherwise noted, we report p-values from Kruskal-Wallis tests (equivalent to a two-sided Wilcoxon rank-sum test when two treatments are being compared).
} 
the average price is 2.03 , again not varying significantly across allocation rules $(\mathrm{p}=0.839)$.

Figure 1 Histograms of prices in payment period by treatment
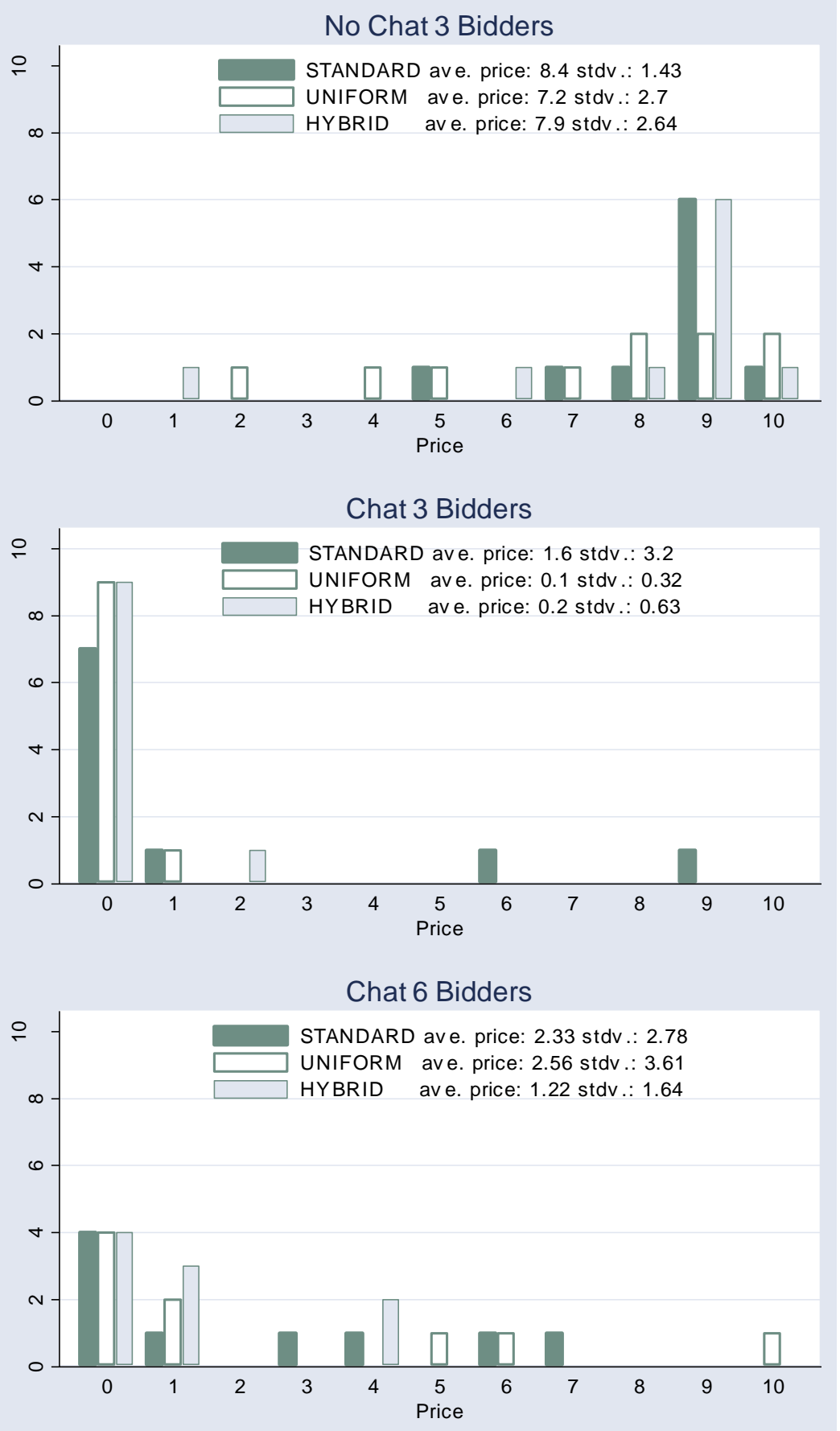

Introducing explicit communication opportunities significantly lowers price: prices are significantly different in our C3 versus NC3 treatments ( $p<0.001$ for each allocation rule). The effect of the number of bidders (C3 vs C6) is much smaller, although significant in the case of 
the UNIFORM and HYBRID rules (STANDARD $\mathrm{p}=0.363$; UNIFORM: $\mathrm{p}=0.029$; HYBRID: $\mathrm{p}$ $=0.047$ respectively) .

In principle, subjects might have used practice periods to coordinate on low-price equilibria in the NC3 treatments, but there is little evidence of this. In contrast, the effectiveness of explicit communication is clear from looking at how market prices vary across periods. Figure 2 presents the time series for each treatment.

Figure 2 Average prices across periods

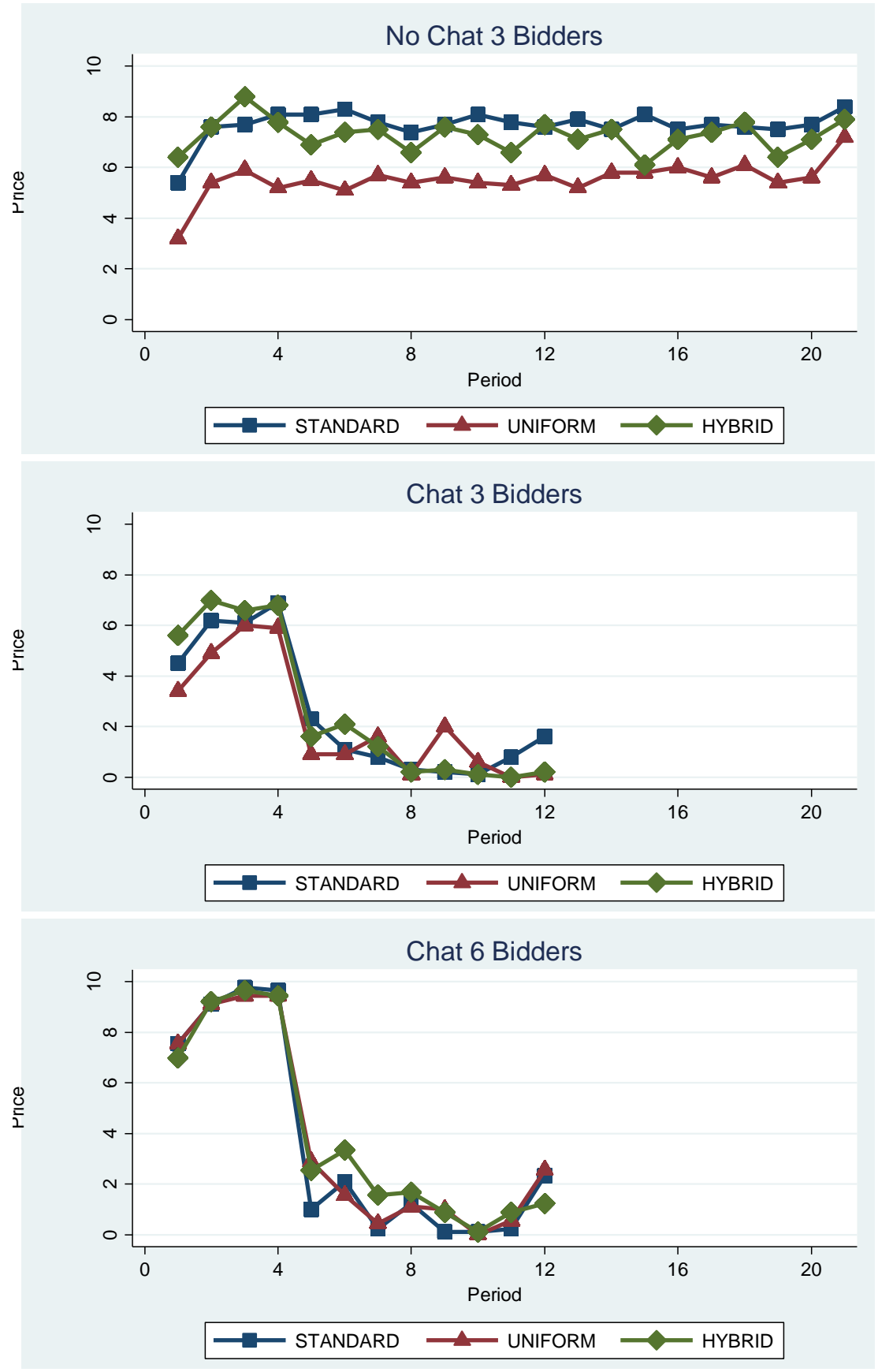


When no chat option is available prices increase in early periods and then remain high for the rest of the session under all three allocation rules. When communication via a chat box becomes available in period five prices drop dramatically. Even in the HYBRID treatments, where the lowest equilibrium price is 7 (C3) or 8 (C6), bidders are able to attain lower prices when they send chat messages.

Result 1: Without explicit communication opportunities prices are competitive under all three allocation rules. Introducing explicit communication opportunities leads to a substantial and significant decrease in price under all three allocation rules. Retaining explicit communication but increasing the number of bidders results in a small increase in the market price, which is statistically significant in UNIFORM and HYBRID.

Next we consider allocations. In panel (a) of Table 3 we report the fraction of groups that attained a perfectly symmetric allocation. The picture across the three allocation rules is similar. Without chat only 1 of 30 groups attained a perfectly symmetric allocation, while 18 of 30 (C3) and 10/27 (C6) attained a perfectly symmetric allocation with chat. Thus, chat messages facilitate equal allocations. Closer inspection of the data from STANDARD showed that while many groups in the $\mathrm{C} 3$ and $\mathrm{C} 6$ treatments coordinated on a perfectly symmetric allocation, those that failed to do so achieved highly asymmetric allocations. Out of 19 groups in the C3 and C6 treatments, eleven failed to coordinate on a symmetric allocation. Across these eleven groups the average standard deviation in allocation was 8.38, notably higher than the variability exhibited in the NC3 treatment. Similar inspection of the UNIFORM data shows that groups that fail to coordinate on a perfectly symmetric allocation nevertheless exhibit less variability than in the NC3 treatment (the average is 5.0625), and the pattern in HYBRID is in between STANDARD and UNIFORM (average variability among groups that failed to coordinate on a perfectly symmetric allocation is 6.41). The variability in allocations, as measured by the standard deviation of the allocation within each group and averaged over groups, is reported in panel (b) of Table 3. In UNIFORM and HYBRID introducing chat results in a significant decrease in variability (UNIFORM: NC3 vs C3 p =0.006, HYBRID: NC3 vs C3 p =0.039). However, in STANDARD we find no significant treatment effects $(\mathrm{p}=0.253)$. Thus although chat promotes collusive prices, under the STANDARD allocation rule it appears to result in one of two extreme effects: either all bidders share the benefit of the low price equally, or else there is a high degree of asymmetry in the distribution of benefits. 
Table 3. Within-Group Variability in Allocations

\begin{tabular}{cccc|ccc}
\hline & \multicolumn{3}{c|}{$\begin{array}{c}\text { Fraction of Groups with } \\
\text { Symmetric Allocation }\end{array}$} & \multicolumn{3}{c}{$\begin{array}{c}\text { (b) } \\
\text { Average Within-Group Standard } \\
\text { Deviation of Allocation }\end{array}$} \\
\hline & NC3 & C3 & C6 & NC3 & C3 & C6 \\
\hline STANDARD & $0 / 10$ & $5 / 10$ & $3 / 9$ & 5.84 & 4.37 & 5.39 \\
\hline UNIFORM & $1 / 10$ & $7 / 10$ & $4 / 9$ & 6.37 & 1.44 & 2.90 \\
\hline HYBRID & $0 / 10$ & $6 / 10$ & $3 / 9$ & 5.50 & 2.45 & 4.40 \\
\hline
\end{tabular}

Result 2. Explicit communication facilitates coordination on symmetric allocations under all allocation rules. This results in lower within-group variability in allocations under UNIFORM and HYBRID allocation rules. Under the STANDARD allocation rule explicit communication results in a higher frequency of highly asymmetric allocations as well as a higher frequency of perfectly symmetric allocations, and so within-group variability in allocations, averaged across groups, is similar across the $\mathrm{NC} 3, \mathrm{C} 3$ and $\mathrm{C} 6$ treatments.

\subsection{Bidder Behavior: No Chat Treatments}

In the no-chat treatments bidding is very heterogeneous and no clear strategy predominates under any allocation rule. In only three of 600 practice periods did bids form an equilibrium. Given this, it is perhaps not surprising that groups failed to coordinate on equilibrium in the payment period. Only two of the 30 payment period auctions resulted in an equilibrium (and these at prices of 8 and 10). Thus there is little evidence of coordination on equilibrium, let alone a low-price equilibrium.

There is some evidence of bidders shading their bids in practice periods and bidding for more units at higher prices in the payment period. Consider bidders' aggregate demand curves, as shown in Figure 3. Average aggregate demand curves are shown for the first ten practice periods, the last ten practice periods, and the payment period. The demand curves for the earlier practice periods and later practice periods are similar in all treatments, but the demand curves for the payment periods clearly shift outwards in all treatments. Most subjects bid more aggressively in the payment period than in the last practice period, by either bidding at a higher price, bidding for more units, or both. ${ }^{12}$

\footnotetext{
${ }^{12}$ Overall, out of 90 subjects 47 bid more aggressively. Of the other subjects 21 bid less aggressively and 22 either bid the same or cannot be classified because they bid more aggressively at some prices and less aggressively at others. The pattern is similar across allocation rules.
} 
Figure 3. Average Aggregate Demand Curves in NC3 Treatments

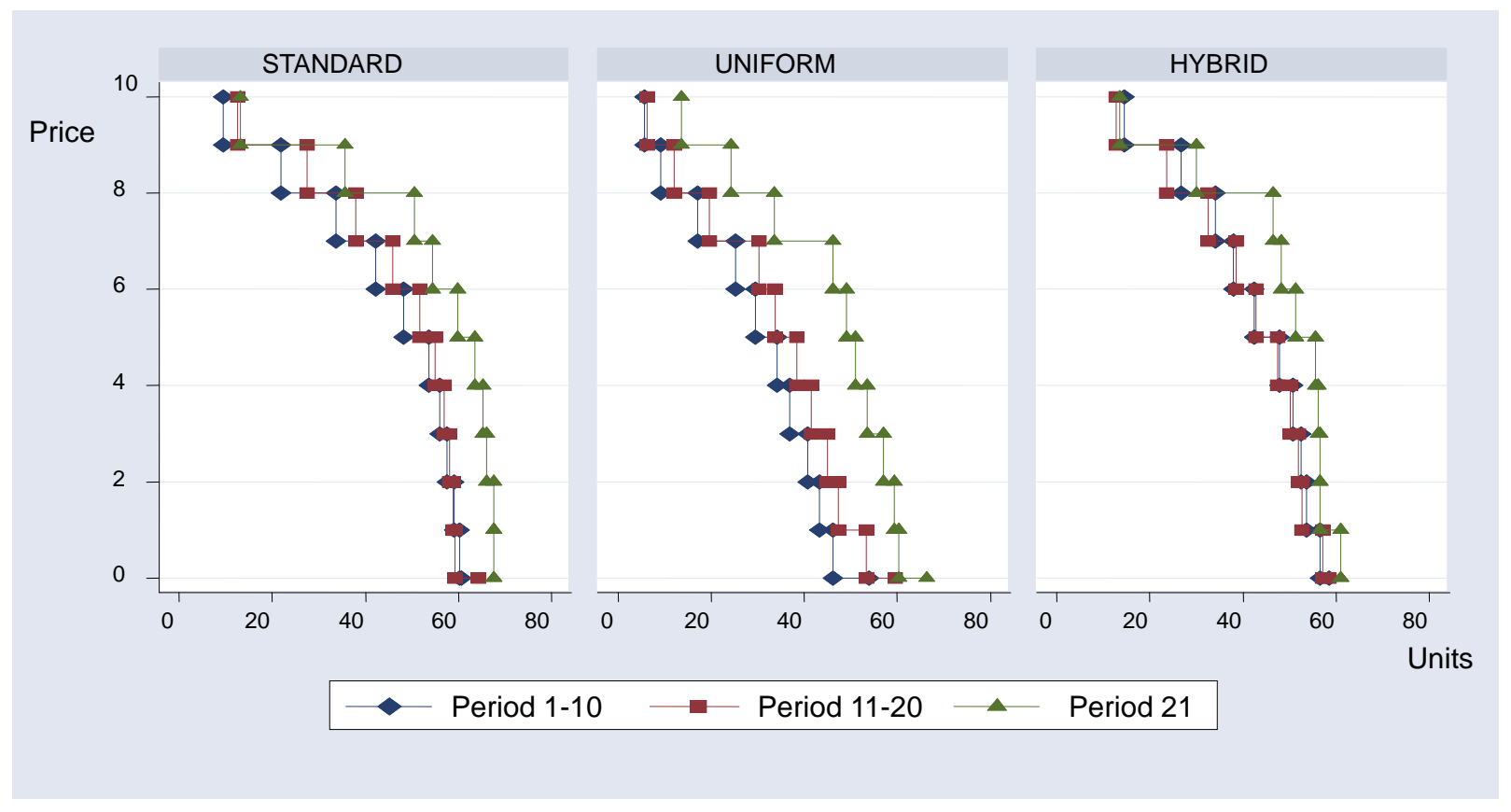

In principle subjects could have used practice periods to coordinate on low-price equilibria, but in fact they did not. Coordination may have been difficult because different bidders were choosing different types of strategies such as flat demand curves or steep demand curves, and without the help of explicit communication it may be difficult to interpret signals sent from other bidders who are following a different strategy. Moreover, some bidders may have been deliberately attempting to mislead rival bidders, bidding low in the practice periods while planning to bid higher in the payment period.

\subsection{Bidder Behavior: Chat Treatments}

We next turn to the chat treatments. Bidder behaviour in periods 1 to 4 , where chat is not available, is not very different from the no-chat treatments. As soon as chat is introduced we begin to observe the development of coordinated strategies in most groups. In almost all groups bidders reached an explicit agreement about what bids to place and kept to the agreement. Some coordinated on the agreement until the end of practice periods, while other groups developed different agreements, sometimes using more sophisticated strategies that made profitable deviation impossible.

Figure 4 shows the proportions of groups where all bidders placed identical bids. Clearly, chat promotes such symmetry under all allocation rules. By the last practice period, most groups (43 out of 57) have settled on symmetric strategies. These strategies vary across groups, but 
invariably lead to a price of zero. ${ }^{13}$ However, there was a clear change in bidding behavior in the payment period: across all allocation rules 26 of 57 groups submitted symmetric strategies.

Figure 4. Proportions of groups where all bidders placed identical bids

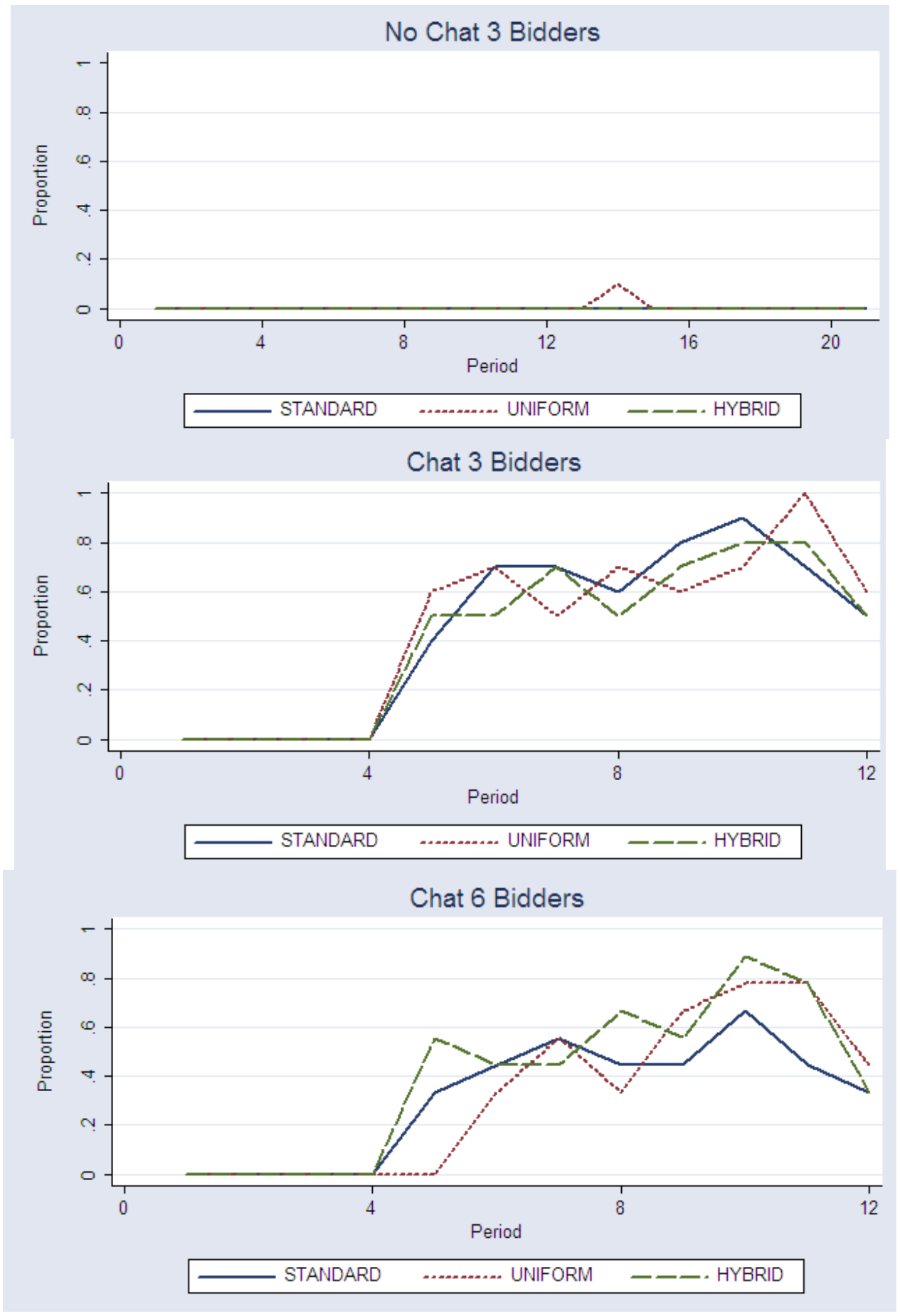

\footnotetext{
${ }^{13}$ The proportion of groups playing symmetric strategies understates the degree to which chat promotes agreements. Some groups agreed on asymmetric strategies that generated a symmetric outcome (e.g. each bidder agreed to bid for 8 units, resulting in a price of zero, but then the bidders submitted their bids at different prices).
} 
Pooling across allocation rules, most strategy combinations can be classified as belonging to one of three categories. In a $T C$ strategy combination bidders submit strategies which would form a TCE under the STANDARD allocation rule. ${ }^{14}$ In a $S B$ strategy combination bidders submit strategies corresponding to a SBE strategy in UNIFORM: all bidders bid for 24 units at a single price. In a Low Demand strategy combination, each bidder bids for a total of 8 units (or 4 in a group of 6) at a price lower than 10, keeping the aggregate group demand below 25 and leading to a market price of zero. Table 4 reports the number of groups in each category in the last practice period and the payment period. Notice that the number of groups submitting TC strategy combinations in the payment period is similar to that in the last practice period. However, compared with the last practice period there are far fewer groups submitting SB or Low Demand strategy combinations.

Table 4. Strategy Combinations in the Chat Treatments

\begin{tabular}{|c|c|c|c|c|c|}
\hline & \multicolumn{4}{|c|}{ Number of groups submitting strategy combinations } & \multirow[b]{2}{*}{ Total } \\
\hline & $\mathrm{TC}$ & SB & Low Demand & Other & \\
\hline Last practice period & 15 & 15 & 11 & 16 & 57 \\
\hline $\mathrm{C} 3$ & 5 & 11 & 6 & 8 & 30 \\
\hline C6 & 10 & 4 & 5 & 8 & 27 \\
\hline Payment period & 13 & 8 & 5 & 31 & 57 \\
\hline C3 & 5 & 7 & 4 & 14 & 30 \\
\hline C6 & 8 & 1 & 1 & 17 & 27 \\
\hline
\end{tabular}

It is interesting to track how the 41 groups that successfully coordinated on a TC, SB or Low Demand strategy combination in the last practice period fared in the payment period. Almost all these groups used the chat stage to agree on doing, in the words of more than one subject, "the same again". However, 17 , or $41 \%$, of the groups deviated from the agreement.

We find that the extent to which a collusive agreement in the last practice period translates to the payment period depends on the incentives for unilateral deviation. For each group we categorize them as "successfully colluding" if they submit exactly the same bids in the payment period as in the last practice period. We calculate the "unilateral deviation gain" in a group to be the highest increase in point earnings that a bidder could have attained by unilaterally changing

\footnotetext{
${ }^{14}$ We also classify as TC some strategy combinations where 24 units are purchased at a price of 0 but the additional unit is ignored: e.g. all bidders submit a single bid for 8 units at a price of 10. These bids do not form an equilibrium, but are similar to the epsilon equilibrium described in Kremer and Nyborg (2004b).
} 
her strategy in the last practice period. ${ }^{15}$ Figure 5 presents histograms of the unilateral deviation gains for the groups that successfully colluded (left panel) and the groups that failed to do so (right panel).

Figure 5. Unilateral Deviation Gain and Successful Collusion

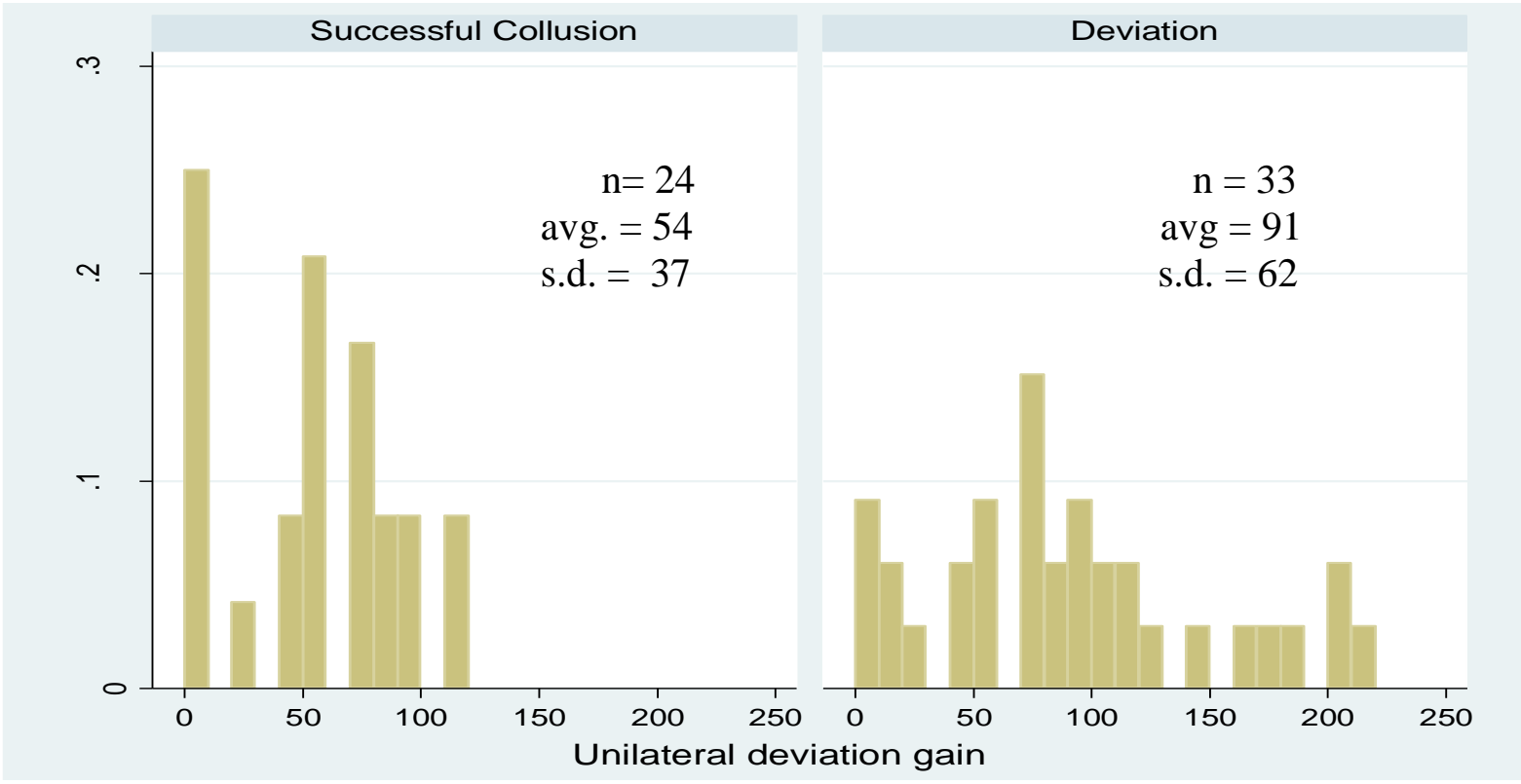

The difference between the two panels is significant ( $p$-value $=0.031)$. It is not always the case that low-price equilibria attained in the last practice period are repeated in the payment period, and sometimes non-equilibrium outcomes in the last practice period are repeated in the payment period. However, the general pattern is that agreements are more stable the lower is the incentive to deviate from them. This may reflect that subjects incur costs from working out ways to increase earnings and small deviation gains do not justify this decision cost. Alternatively, subjects may incur psychological costs from breaking promises or misleading other group members and small deviation gains do not justify incurring these costs. We summarize as follows:

Result 3. Explicit communication opportunities enable bidders to coordinate on strategies that generate low price outcomes in practice periods. The extent to which this coordination translates to the payment period depends on the type of strategy and

\footnotetext{
${ }^{15}$ For example, suppose a group uses the symmetric TC strategy combination of bidding for 8 units at 10 (or 4 units at 10 with 6 bidders) and the remaining units at 0 . This results in a payoff of 83.33 (or 41.67 with 6 bidders) per bidder. In SC3 this is an equilibrium and so the unilateral deviation gain would be zero. In the other treatments the most profitable unilateral deviation would be to bid for the remaining units at a price of 1 . This increases the deviator's payoff by 51.67 (UC3) or 24.67 (HC3), and by 3.33 (SC6), 81.11 (UC6), or 42.33 (HC6).
} 
incentives for unilateral deviation. Strategies that offer lower unilateral gains from deviation are more stable than strategies offering higher gains.

\subsection{Comparison of Strategy Combinations and Allocation Rules}

The extent to which strategy combinations are vulnerable to deviation is related to the type of strategy, the allocation rule, and the number of bidders. The analysis of unilateral deviation gain suggests that agreements are more fragile the greater the gain from a unilateral deviation, and so one might expect TC strategies to be stable in STANDARD, where they form an equilibrium, and less so in other allocation rules. In fact this is the case: under the STANDARD allocation rule all five of the groups using a TC strategy combination in the last practice period also submitted a TC strategy combination in the payment period, while under the other allocation rules ten groups used TC strategy combinations in the last practice round but four of them changed in the payment period.

The finding that TC strategy combinations, once achieved, are stable under the STANDARD allocation rule shows that the STANDARD allocation rule is susceptible to collusive equilibria, at least when bidders can explicitly communicate. Interestingly, we find this to be as true for six-bidder groups as for three-bidder groups, reinforcing a point made by Wilson (1979) that sellers may not benefit from an increase in the number of bidders under this allocation rule.

One might also expect SB strategies to be more stable in UNIFORM, where they form an equilibrium, than under other allocation rules. This, however, is not observed in the data: under UNIFORM two of five groups stayed with SB strategies after using them in the last practice period. This compares with six of ten groups under the other allocation rules.

Result 4: TC strategies featuring steep demand curves are more stable than SB strategies featuring flat demand curves. In particular under the STANDARD allocation rule agreements to play TC strategy combinations in STANDARD are always kept, while under the UNIFORM allocation rule agreements to play SB strategy combinations usually fail.

One explanation for why SB strategies are more fragile than TC strategies may be the following. In STANDARD, if a bidder unilaterally deviates from a TCE by bidding more aggressively she will suffer a reduced payoff. In UNIFORM, if a bidder unilaterally deviates from a SBE by raising her bid she will not change the price or allocation and so her payoff will 
not change. Thus a unilateral deviation from SBE in UNIFORM does not make a bidder better off or worse off. Moreover, if a bidder worries that others may raise their bids her best response will be to raise her bid as well rather than following her SB strategy.

This may also explain why SB strategies are particularly infrequent in our C6 treatments. As shown in Table 4, of 30 groups in our C3 treatments 11 submit SB strategies in the last practice period and 7 submit SB strategies in the payment period. By comparison, only 4 of 27 groups in the C6 treatments submitted SB strategies in the last practice period and only 1 group submitted SB strategies in the payment period. It may be that subjects are less confident that all bidders will follow an SB strategy in a six-bidder group, and this makes playing an SB strategy less attractive.

Result 5: TC strategies featuring steep demand curves are more frequently used in sixbidder than three-bidder groups. In contrast SB strategies featuring flat demand curves are used less frequently in six-bidder than three-bidder groups.

\section{DISCUSSION AND CONCLUSIONS}

We find little evidence of revenue differences due to alternative allocation rules for uniform price auctions. In our no chat treatments subjects play repeatedly in practice periods before playing a single auction for payment, and so in principle can communicate via decisions in practice periods in order to coordinate on low-price equilibria. However, we find bidding is competitive under all three allocation rules. Introducing explicit communication opportunities by allowing bidders to send messages via a chat box before placing bids leads to a substantial and significant decrease in the market price: low prices are observed under all three allocation rules. The effectiveness of explicit communication is reminiscent of the result that communication plays a more important role than repeated play in fostering successful collusive agreements in first price sealed bid auctions (Kwasnica, 1998). The effectiveness of explicit communication for facilitating collusion is also in line with the results of Goswami, Noe, and Rebello (1996), who study a similar setting to ours and also find that non-binding pre-play communication increases bidders' tendency to play collusive strategies in uniform price auctions under the standard allocation rule. ${ }^{16}$

A closer look at bidding behavior in the chat treatments reveals that different groups

\footnotetext{
${ }^{16}$ Sade, Schnitzlein and Zender (2006) also conduct experiments with uniform price auctions under the standard rule, allowing communication. They only report on "perfect collusion", in which all bidders bid the same amount at the lowest permissible price. This corresponds to our SB strategy combination at a price of zero. In their experiment four out of thirteen groups follow this strategy, while in our STANDARD C3 and C6 treatments three out of nineteen groups follow this strategy.
} 
attained low prices in different ways. In three-bidder groups, a particularly frequent strategy combination consists of single bid strategies whereby bidders submit flat demand functions at a common price. In six-bidder groups such strategies are observed less frequently, and instead we more often observe tacit collusion strategies whereby bidders submit steep demand functions. We also observe that while many groups agreed to submit the same bids in the payment period as in the last practice period, these agreements were not always kept. In general, the success of an agreement depended on the incentives for unilateral deviation and the type of strategy. Strategies that offer low unilateral gains from deviation are more stable than strategies offering higher gains, and single-bid strategies are vulnerable even under the uniform allocation rule where they form an equilibrium. In contrast, groups that followed tacit collusion strategies in practice periods tended to rely on these in the payment period as well.

Although the stability of different types of strategy depends on the allocation rule, this does not translate into price differences. The reason is that many bidders keep to non-equilibrium agreements, and in groups where there is a deviation it is often only a single bidder who deviates and this results in the deviator receiving a higher allocation but not paying a higher price. In sixbidder groups non-equilibrium agreements are more vulnerable, but at the same time bidders protect themselves by coordinating on different strategy combinations. In particular steep demand curves are frequently submitted. These are more complex but have the advantages that they give a smaller incentive to deviate and also allow the bidder to secure some allocation even if other bidders deviate. Moreover, under the standard rule these strategies form an equilibrium and when groups agree to use these strategies in practice periods they subsequently stay with the equilibrium in the payment period. An implication is that the standard allocation rule is more susceptible to collusive equilibria, at least when bidders can explicitly communicate. 


\section{REFERENCES}

Ausubel, L. and Cramton, P. "Auctioning Many Divisible Goods." Journal of the European Economic Association, Vol. 2 (2004), pp. 480-493.

Back, K. and Zender, J.. "Auctions of Divisible Goods: On the Rationale for the Treasury Experiment." The Review of Financial Studies, Vol. 6 (1993), pp. 733-764.

Brown, A., Plott, C. and Sullivan, H. "Collusion Facilitating and Collusion Breaking Power of Simultaneous Ascending and Descending Price Auctions." Economic Inquiry, Vol. 47 (2009), pp. 395-424.

Burton, A. and Sefton, M. "Risk, Pre-play Communication and Equilibrium." Games and Economic Behavior, Vol. 46 (2004), pp. 23-40.

Burtraw, D., Goeree, J., Holt, C., Myers, E., Palmer, K. and Shobe, W. "Collusion in Auctions for Permission Permits: An Experimental Study." Journal of Policy and Management. (forthcoming).

Devetag, G. and Ortmann, A. "When and why? A critical survey on coordination failure in the laboratory." Experimental Economics. Vol. 10 (2007), pp. 331-344.

Engelmann, D. and Grimm, V. "Bidding Behavior in Multi-unit Auctions: An Experimental Investigation." The Economic Journal, Vol. 119 (2009), pp. 855-882.

Fischbacher, U. "z-Tree: Zurich Toolbox for Ready-made Economic Experiments.” Experimental Economics Vol. 10 (2007), pp. 171-178.

Füllbrunn, S., and Neugebauer, T. "Anonymity Deters Collusion in Hard-close Auctions: Experimental Evidence." New Zealand Review of Economics, Vol. 43 (2007), pp. 131-148.

Goeree, J., Offerman, T. and Sloof, R. "Demand Reduction and Preemptive Bidding in Multi-unit License Auctions." CEPR Discussion Papers 4899 (2006).

Goswami, G., Noe, T. and Rebello, M. "Collusion in Uniform-Price Auctions: Experimental Evidence and Implication for Treasury Auctions." The Review of Financial Studies, Vol. 9 (1996), pp. 757-785.

Greiner B. "The Online Recruitment System ORSEE 2.0 - A Guide for the Organization of Experiments in Economics." University of Cologne, Working Paper Series in Economics 10 (2004).

Issac, R. and Walker, J. "Information and Conspiracy in Sealed Bid Auctions." Journal of Economic Behavior and Organization, Vol. 6 (1985), pp. 139-159.

Kagel, J. and Levin, D.. "Behavior in Multi-unit Demand Auctions: Experiments with Uniform Price and Dynamic Vickrey Auctions.” Econometrica, Vol. 69 (2001), pp. 413-454.

Klemperer, P. and Meyer, M. "Supply Function Equilibria in Oligopoly under Uncertainty." Econometrica, Vol. 57 (1989), pp. 1243-1277. 
Kremer, I. and Nyborg, K. "Divisible Good Auctions: The Role of Allocation Rules." Rand Journal of Economics, Vol. 35 (2004a), pp. 147-159.

Kremer, I. and Nyborg, K. "Underpricing and Market Power in Uniform Price Auctions." The Review of Financial Studies, Vol. 17 (2004b), pp. 849-877.

Kwasnica, A. "Collusion in Multiple Object Simultaneous Auctions: Theory and Experiments." Caltech Social Science working paper 1010 (1998).

Kwasnica, A. "The Choice of Cooperative Strategies in Sealed Bid Auctions." Journal of Economic Behavior and Organization, Vol. 42 (2000), pp. 323-346.

Kwasnica, A. and Sherstyuk, K. "Collusion and Equilibrium Selection in Auctions." The Economic Journal, Vol. 117 (2007), pp. 120-145.

Li, J. and Plott, C. "Tacit Collusion in Auctions and Conditions for Its Facilitation and Prevention: Equilibrium Selection in Laboratory Experimental markets." Economic Inquiry, Vol. 47 (2009), pp. 425-448.

Porter, D.and Vragov, R. "An Experimental Examination of Demand Reduction in Multi-Unit Versions of the Uniform-Price, Vickrey, and English Auctions." Managerial and Decision Economics, Vol. 27 (2006), pp. 445-458.

Sade, O., Schnitzlein, C. and Zender, J. "Competition and Cooperation in Divisible Good Auctions: An Experimental Examination.” The Review of Financial Studies, Vol. 19 (2006), pp. 195-235.

Sherstyuk, K. "Collusion without Conspiracy: An Experimental Study of One-Sided Auctions." Experimental Economics, Vol. 2 (1999), pp. 59-75.

Sherstyuk, K. "Some Results on Anti-Competitive Behavior in Multi-Unit Ascending Price Auctions." In Plott, C., Smith, V. Eds., Handbook of Experimental Economics Results. Amsterdam: Elsevier, 2008.

Smith, V. "Experimental Studies of Discrimination versus Competition in Sealed-bid Auction Markets." Journal of Business Research, Vol.40 (1967), pp. 56-84.

Wang, J. and Zender, J. “Auctioning Divisible Goods.” Economic Theory, Vol. 19 (2002), pp. 673-705.

Wilson, R. "Auctions of Shares." The Quarterly Journal of Economics, Vol. 93 (1979), pp. 675689.

Zhang, P. "Uniform Price Auctions and Fixed Price Offerings in IPOs: An Experimental Comparison.” Experimental Economics, Vol. 12 (2009), pp. 202-219. 


\section{APPENDIX}

The instructions below are for three-bidder treatments. Instructions for six-bidder treatments are similar. Text that differs across treatments with different allocation rules appears in square brackets and indicated with S (for STANDARD), U (for UNIFORM) or H (for HYBRID). Text that differs in treatments with or without the chat stage appears in braces and starts with $\mathrm{C}$ (for treatments with the chat stage) or NC3 (for treatments without the chat stage).

\section{Instructions}

Welcome! You are about to take part in an experiment in the economics of decision making. You will be paid in private and in cash at the end of the experiment. You will be paid a participation fee of five pounds, plus an additional amount that will depend on your decisions. How this additional amount is determined is explained in these instructions, so please follow the instructions carefully.

It is important that you do not talk to any of the other participants until the experiment is over. If you have a question at any time, raise your hand and a monitor will come to your desk to answer it.

\section{Description of the Experiment}

The experiment will consist of $\{\mathrm{C}: 12\}$ \{NC3: 21$\}$ periods. In each period you will be in a group of three bidders. At the beginning of the experiment, the computer will randomly form groups of three bidders from the participants in the room. A bidder ID, which is either A or B or C will be allocated to you randomly. You will be in a group with the same two other participants throughout the experiment. No participant will ever learn the identities of the other members of his group in any period.

In each period you can earn points. The first $\{\mathrm{C}$ : eleven $\}$ NC3: twenty $\}$ periods will be practice periods in order to help you understand the experimental rules and the experimental environment. The points you earn in these periods will NOT count towards your final earnings. Your point earnings in period $\{\mathrm{C}$ : twelve $\}$ NC3: twenty-one $\}$ will be converted to British Pounds at the exchange rate of 1 point $=20$ pence to determine your additional earnings. You will be paid the participation fee and your additional earnings at the end of the experiment.

$\{\mathrm{C}$ : From period five there will be up to four minutes for communication at the beginning of each period. You will be able to communicate with the other two bidders through a message box on your computer screen. You are free to discuss any aspect of the experiment that you wish, except that:

- You must not reveal any personal information (for example, your name, where you are seated in the lab, where you live, your email address or phone number, etc.).

- No threatening, insulting or offensive comments are allowed.

If you violate these rules your payment will be forfeited. 


\section{Description of a Period}

In each period there are 25 units for sale in each group. You buy units by submitting bids. A bid is a price-quantity pair indicating how many units you bid for at which price. You can submit multiple bids, as long as the total number of units you bid for does not exceed 24 units. Thus, the most any bidder can bid for is less than the total number of units for sale. After all bidders have submitted their bids, the computer calculates a market price and allocates units among bidders. For each unit allocated to you, you receive 10 points and pay the market price. The market price rule and the allocation rule will be explained shortly.

At the beginning of each period you will see a bidding box on your computer screen (see Figure 1). To place a bid you enter a price and the number of units that you bid for at that price in the corresponding boxes, then click on the "Place this Bid" button. A price must be an integer between 0 and 10. The number of units must be an integer between 0 and 24 .

After you click on the "Place this Bid" button, your bid will appear in the table on the right of your screen (see Figure 2). Repeat the above procedure if you want to place multiple bids. Your bids will be sorted by price from high to low in the table. The total number of units that you have bid for is shown above the table (see Figure 2).

At any time before the final submission of bids, you can withdraw a bid that you have placed. To do this click on the bids that you wish to withdraw from the table (the bids then will be highlighted), then click on the "Withdraw a Bid" button. If you want to withdraw all bids that you have placed, simply click on the "Clear All Bid(s)" button.

When you are ready, click on the "Final Submission" button to submit your bids. After all members in your group have finally submitted their bids, the computer calculates the market price and allocates units among your group.

You will then be informed of the bids submitted by your group, the market price, your allocation and your profit for the period. The period then ends and the next period begins.

\section{Market Price and Allocation Rules}

If the total number of units your group bids for is less than 25 , the market price will be zero and each group member will obtain the number of units he or she bid for.

[S: If the total number of units your group bids for is greater than or equal to 25 , the market price will be the highest price at which all 25 units can be sold. Bids placed above the market price will be fully fulfilled. The remaining units will be allocated proportionately among the bid(s) placed at the market price. ]

[U: If the total number of units your group bids for is greater than or equal to 25 , the market price will be the highest price at which all 25 units can be sold. The 25 units will be allocated proportionately among all winning bids, i.e. bids placed at or above the market price. ]

[H: If the total number of units your group bids for is greater than or equal to 25, the market price will be the highest price at which all 25 units can be sold. Two methods will then be used to allocate the units. According to the first method, the 25 units will be allocated proportionately among all winning bids, i.e. bids placed at or above the market price. According to the second 
method, bids placed above the market price will be fully fulfilled, and the remaining units will be allocated proportionately among the bid(s) placed at the market price. Your allocation in each period will be the average of the allocation based on the two methods.]

We use three examples to demonstrate how the market price and allocation rules work. The examples are based on a table that is similar to the table that will be displayed on your screen at the end of each period. However, in the examples prices range up to 30, while in the experiment prices range between 0 and 10. Also the bids in the experiment will be determined by the participants' choices. In all examples the column headed "Units Group Bids for" is the sum of the columns headed "Units You Bid for" and "Units Other Group Members Bid for". The column headed "Accumulated Units Group Bids for" shows the number of units bid for by your group at and above the corresponding price. The line corresponding to the market price will appear in blue on your screen.

\section{Example 1:}

\begin{tabular}{|c|c|c|c|c|}
\hline Price & Units You Bid for & $\begin{array}{c}\text { Units Other Group } \\
\text { Members Bid for }\end{array}$ & $\begin{array}{c}\text { Units Group Bids } \\
\text { for }\end{array}$ & $\begin{array}{c}\text { Accumulated Units } \\
\text { Group Bids for }\end{array}$ \\
\hline 30 & 6 & 0 & 6 & 6 \\
26 & 0 & 10 & 10 & 16 \\
23 & 5 & 3 & 8 & 24 \\
0 & 0 & 0 & 0 & 24 \\
\hline
\end{tabular}

In Example 1, the total number of units that your group bids for is 24, which is less than 25 . Thus the market price is zero and you obtain the total number of units you bid for, which is 11 units.

\section{Example 2:}

\begin{tabular}{|c|c|c|c|c|}
\hline Price & Units You Bid for & $\begin{array}{c}\text { Units Other Group } \\
\text { Members Bid for }\end{array}$ & $\begin{array}{c}\text { Units Group Bids } \\
\text { for }\end{array}$ & $\begin{array}{c}\text { Accumulated Units } \\
\text { Group Bids for }\end{array}$ \\
\hline 30 & 6 & 0 & 6 & 6 \\
26 & 0 & 10 & 10 & 16 \\
23 & 5 & 4 & 9 & 25 \\
0 & 0 & 0 & 0 & 25 \\
\hline
\end{tabular}

Compared with Example 1, the only difference in Example 2 is that at price 23 the other group members bid for 4 units. The highest price at which all 25 units can be sold is 23 . Thus the market price is 23 .

[S: Bids placed above the market price are fully fulfilled. Thus you are allocated 6 units and the other group members are allocated 10 units. This leaves 9 units to be allocated proportionately among the bids placed at the price of 23. Since the group bids for 9 units at a price of 23, each bid is fully fulfilled. Thus you are allocated an additional 5 units. In total you are allocated 11 units.]

[U: The units are allocated to all winning bids, i.e. bids placed at or above the market price. There are 25 units available and the group bids for 25 units at or above the market price. Hence each unit bid for at or above the market price is fully fulfilled. Thus you obtain 11 units.] 
[H: Two methods are used to allocate the units. According to the first method, the units are allocated to all winning bids, i.e. bids placed at or above the market price. There are 25 units available and the group bids for 25 units at or above the market price. Hence each unit bid for at or above the market price is fully fulfilled. Thus your allocation following the first method is $\mathbf{1 1}$ units.

According to the second method, bids placed above the market price are fully fulfilled. Thus you are allocated 6 units and the other group members are allocated 10 units. This leaves 9 units to be allocated proportionately among the bids placed at the price of 23. Since the group bids for 9 units at a price of 23, each bid is fully fulfilled. Thus you are allocated an additional 5 units. Your allocation following the second method is $\mathbf{1 1}$ units in total.

Your final allocation is the average of the allocation based on the two methods, i.e. $(11+11) / 2=11$ units.]

\section{Example 3:}

\begin{tabular}{|c|c|c|c|c|}
\hline Price & Units You Bid for & $\begin{array}{c}\text { Units Other Group } \\
\text { Members Bid for }\end{array}$ & $\begin{array}{c}\text { Units Group Bids } \\
\text { for }\end{array}$ & $\begin{array}{c}\text { Accumulated Units } \\
\text { Group Bids for }\end{array}$ \\
\hline 30 & 6 & 0 & 6 & 6 \\
26 & 0 & 16 & 16 & 22 \\
23 & 5 & 4 & 9 & 31 \\
0 & 0 & 0 & 0 & 31 \\
\hline
\end{tabular}

Compared with Example 2, the only difference in Example 3 is that at price 26 the group bids for 16 units. The highest price at which all 25 units can be sold is 23 . Thus the market price is 23 .

[S: Bids placed above the market price are fully fulfilled. Thus you are allocated 6 units and the other group members are allocated 16 units. This leaves 3 units to be allocated proportionately among the bids placed at the price of 23. Since the group bids for 9 units at a price of 23, a bidder receives $3 / 9$ of a unit for each unit he or she bid for at this price. Thus you are allocated an additional $5 \times 3 / 9=1.667$ units. In total you are allocated 7.667 units.]

[U: The units are allocated proportionately among all winning bids, i.e. bids placed at or above the market price. There are 25 units available and the group bids for 31 units at or above the market price. Hence a bidder receives $25 / 31$ of a unit for each unit he or she bid for at or above the market price. Thus you are allocated $11 \times 25 / 31=8.871$ units.]

[H: Two methods are used to allocate the units. According to the first method, the units will be allocated proportionately among all winning bids, i.e. bids placed at or above the market price. There are 25 units available and the group bids for 31 units at or above the market price. Hence a bidder receives $25 / 31$ of a unit for each unit he or she bid for at or above the market price. Thus your allocation following the first method is $11 \times 25 / 31=\mathbf{8 . 8 7 1}$ units.

According to the second method, bids placed above the market price are fully fulfilled. Thus you are allocated 6 units and the other group members are allocated 16 units. This leaves 3 units to be allocated proportionately among the bids placed at the price of 23. Since the group bids for 9 units at a price of 23, a bidder receives 3/9 of a unit for each unit he or she bid for at this price. Thus you are allocated an additional $5 \times 3 / 9=1.667$ units. Your allocation following the second method is $\mathbf{7 . 6 6 7}$ units in total. 
Your final allocation is the average of the allocation based on the two methods, i.e. $(8.871+7.667) / 2=8.269$ units.]

\section{Your Earnings}

In each period you receive 10 points for each unit allocated to you and pay the market price for each unit allocated to you. Thus, your profit in points in a period is:

Your profit $=(10-$ market price $) \times$ number of units allocated to you

Remember, the first eleven periods are just for practice. The points you earn in these periods will not affect your final cash earnings.

Your profits from the last period, period $\{\mathrm{C}: 12\}\{\mathrm{NC} 3: 21\}$, will determine your cash earnings. Your profit in period $\{\mathrm{C}: 12\}\{\mathrm{NC} 3: 21\}$ will be converted into British Pounds at a rate of twenty pence per point.

\section{Beginning the Experiment}

We are now ready to begin the experiment. Please look at your screen and follow the prompts. If you have a question at any time please raise your hand. 
Please input a bid in the boxes below:

Price per Unit:

(Input an integer between 0 and 10)

Number of Units:

(Input an integer between 0 and 24)

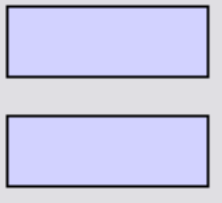

Place this Bid

\section{[Figure 1]}

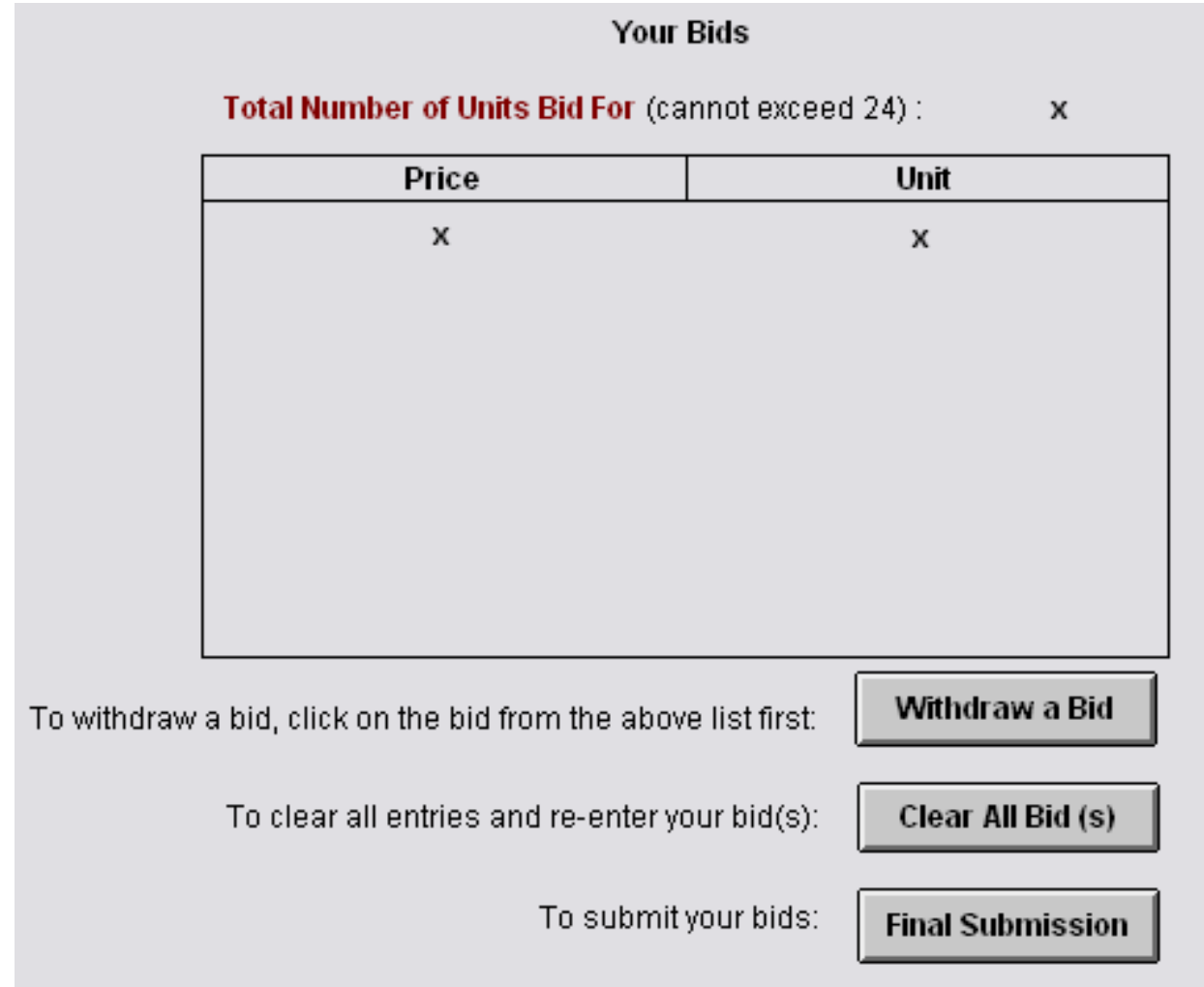

[Figure 2] 